\title{
Taking the pulse of Canadian health information professionals: Canadian Health Libraries Association / Association des bibliothèques de la santé du Canada (CHLA / ABSC) 2010 survey
}

\author{
Orvie Dingwall, Marlene Dorgan, Rebecca Raworth, and Miriam Ticoll
}

\begin{abstract}
In August 2010, the Canadian Health Libraries Association / Association des bibliothèques de la santé du Canada (CHLA / ABSC) distributed a survey to its members and the larger health library community in Canada. The purpose of the survey was to guide the CHLA / ABSC Board of Directors in creating the 2011-2013 Strategic Plan, to understand the demographics of health information professionals in Canada, and to understand the perceived value of CHLA / ABSC membership. Of the 186 respondents, 157 were current CHLA / ABSC members, representing $46 \%$ of the membership. This article examines the results of this survey and also compares the results to similar surveys CHLA / ABSC administered in 2001 and 2008.
\end{abstract}

\section{Background and objectives}

In 2001 the Canadian Health Libraries Association / Association des bibliothèques de la santé du Canada (CHLA / ABSC) celebrated its 25th anniversary and determined it was an appropriate time to learn more about the Association's membership and the landscape of health information professionals in Canada [1]. This was the first time since the founding of CHLA / ABSC that a survey of health librarians in Canada had been conducted [2]. In 2008, the CHLA / ABSC Board of Directors administered a survey to its members to guide the creation of a strategic plan, and to understand the value of CHLA / ABSC as it was perceived by its members, and why members join CHLA / ABSC [3,4].

The current survey was administered with similar objectives in mind. As with the 2008 survey, the Board believed that for the Association to remain relevant and valuable, members need to be surveyed and given a formal opportunity to provide input. As was the case with the 2001 survey, current members of CHLA / ABSC, as well as non-members, were encouraged to respond. The Board wanted to gain a better understanding of the full spectrum of health information professionals in Canada, including CHLA / ABSC members, health information professionals who are members of their local chapters but are not CHLA / ABSC members, as well as those who are not members of a Canadian health library association. The objectives for the 2010 survey were to:

- seek input from members and potential members regarding the focus of CHLA / ABSC in the next 2-5 years to help guide the creation of the 2011-2013 Strategic Plan;

- understand the perceived benefits of membership of current and potential members; and

- learn more about the demographics of the Canadian health library community.

\section{Methods}

A bilingual survey was created that included many questions from the 2001 and 2008 surveys to allow for comparison over time. After much consideration, it was decided to make the survey available on two platforms: Survey Monkey and Drupal. The previous surveys had utilized the Survey Monkey platform, but some provinces and institutions in Canada have since blocked Survey Monkey. There was no cost to build the Drupal survey on the CHLA / ABSC website, though the robustness of the analysis features was unknown. Results

O. Dingwall. ${ }^{1}$ Neil John Maclean Health Sciences Library, University of Manitoba, 770 Bannatyne Ave. Winnipeg, MB R3E 0W3, Canada.

M. Dorgan. John W. Scott Health Sciences Library, University of Alberta, 2K3.28 WCM Health Sciences Centre, Edmonton, AB T6G 2R7, Canada.

R. Raworth. University of Victoria, PO Box 1800, Station CSC, Victoria, BC V8W 3H5, Canada.

M. Ticoll. Health Science Information Consortium of Toronto, 110 Sussex Ave. Toronto, ON M5S 1K3, Canada.

${ }^{1}$ Corresponding author (e-mail: orvie_dingwall@umanitoba.ca). 
submitted through the Drupal survey were re-entered into Survey Monkey, enabling analysis on a single platform. The survey was distributed by e-mail to CHLA / ABSC members, through the CANMEDLIB listserv, and on the CHLA / ABSC website. CHLA / ABSC Chapter Presidents were encouraged to distribute the survey on their chapter listservs. The survey was open for two weeks. Two reminders were sent after the initial announcement of the survey.

The survey included two mandatory questions and utilized a mixture of multiple choice, rating scale, and open-ended questions. It was divided into the following five sections:

1. Association Information - The first mandatory question was whether respondents were current members of CHLA / ABSC. Other questions pertained to involvement in the Association and (or) its Chapters.

2. Trends - The second mandatory question asked what CHLA / ABSC should focus on in the next 2-5 years. The other question inquired about predicted changes in work environments and their potential impact(s).

3. Association Services - Primarily drawn from the 2008 survey, these questions pertained to the Association's services, benefits of membership, the need for development of guidelines, and advocacy issues.

4. Communication - Primarily drawn from the 2008 survey, these questions focused on methods for distributing information and networking opportunities.

5. Demographics - These questions pertained to respondents' years of experience, age range, salary, level of education, nature of employment, job position, and type of library.

\section{Results}

Results of the survey will be posted on the Association's web site at www.chla-absc.ca.

\section{Association Information}

One of the two mandatory survey questions was whether respondents were current members of CHLA / ABSC. Of the 186 survey respondents, 157 indicated that they were members, which represents $46 \%$ of the membership. The 29 respondents who were not currently CHLA / ABSC members were asked to describe why they were not a member. Common responses were that membership was too expensive; that organizations could not or would not pay for membership; or, that they were a member of another health library association instead, such as their local chapter. Nearly $80 \%$ (139) of respondents indicated that they were members of their local chapter. Of the 29 respondents who were not current members of CHLA / ABSC, 12 (41.4\%) were members of their local chapter.

Nearly half of the respondents $(45 \%)$ indicated that they were actively involved in CHLA / ABSC activities, including being on the executive of their local chapter $(29 \%)$, participating in the Mentorship Interest Group $(20 \%)$ or on a Conference Planning Committee $(19 \%)$, contributing to the journal JCHLA (18\%), or participating in the Open Access Interest Group (13\%). Similar to the results from 2008 , almost an equal number of members have held membership for $1-5$ years $(34.8 \%)$ as those who have been members for more than 10 years $(28.7 \%)$.

\section{Trends}

In the Trends section of the survey, respondents were asked two open-ended questions. The first question was mandatory and though 186 respondents started the survey, not all of them completed it. Only 152 respondents replied to the question "What would you like CHLA / ABSC to focus on in the next 2-5 years?" Four themes emerged and are listed in order of importance:

\section{Continuing education $(\mathrm{CE})$}

This survey did not focus on CE but at least one-third of respondents indicated that more $\mathrm{CE}$ offerings would be appreciated. A number of respondents noted the need for opportunities to participate virtually. This was of particular importance for those in rural environments, in smaller healthcare settings, or those unable to attend the CHLA / ABSC annual conference.

\section{Advocacy}

CHLA / ABSC's role as an advocacy organization was identified in two parts: to more actively promote health science librarianship in the library community and to advocate for health science librarianship in the broader Canadian health community. Suggestions included developing tools to promote libraries in hospitals and healthcare settings and associations; bench-marking library services; and advocating "for hospital librarians where there are none". Concern was expressed about hospital library closures or hospital librarians retiring and being replaced by library technicians. A number of respondents suggested that CHLA I ABSC advocate for broad issues (e.g., copyright, open access, and the future of health libraries) and strengthen its partnerships by networking with other library associations, such as the Canadian Library Association (CLA) and the Medical Library Association (MLA).

\section{Support consortia, licensing of electronic resources, and the Canadian Virtual Health Library}

Ongoing and continuing support for the Canadian Virtual Health Library / Bibliothèque virtuelle canadienne de la santé (CVHL / BVCS) was mentioned as a priority area by approximately 20 respondents, and another 10 indicated the need to leverage consortia purchases and (or) develop national licenses. Respondents specified that "a pan-Canadian e-library" was needed and that CHLA / ABSC should "help health libraries access electronic journals at an economical price through a consortium".

\section{Accreditation and standards}

Accreditation and standards were frequently mentioned, particularly with regard to concerns about hospital library closures. For some respondents accreditation related specifically to hospital standards through Accreditation Canada; whereas, others referred to developing standards for librarians. One respondent emphasized that "Hospital library standards... are essential to the ....hospital library members of CHLA. There has been a lot done in the past few years, and we absolutely must sustain the work to keep hospital libraries explicitly named in the Accreditation [Canada] standards." 


\section{Trends: impact of changes in work environment}

The second question in the Trends section asked: What changes in your work environment will have the most impact on your role in the next few years? The four themes that emerged from the 134 responses are as follows:

1. Budget cuts, downsizing, retirements, and doing more with less.

This cluster of issues was the most frequently mentioned by respondents. Concerns were expressed about the de-professionalization and diminishment of library services. A number of respondents noted the trend towards not replacing retiring librarians or replacing them with library technicians.

\section{Continuous technological change and ongoing digitization.}

Many respondents noted the continued digitization of print resources, the importance of librarians' awareness and involvement in the electronic health record, and other ongoing technical innovations, including social media and mobile device applications. One respondent explained that "Electronic books, e-readers and mobile devices will change how and what we collect and how we deliver information to our clients. The CVHL will also have a significant impact."

3. Changes to the library profession.

The responses demonstrated an overall sense that the library profession is in transition. There were conflicting perceptions as to whether these changes were positive or negative. Some of the changes mentioned were an increase in virtual work with fewer face-to-face interactions; an increasing focus on project work, research, and instructional activities; opportunities to utilize communities of practice; and the possibility of contributing more decision-support in clinical settings.

4. The impact of the broader health environment on health libraries.

Changes to the structure of healthcare delivery in provincial and (or) territorial jurisdictions were mentioned, although there were differing views on the impact on libraries. One respondent referred to regionalization of health care in their province as a possible threat to libraries; whereas, others noted that regionalization of health service delivery was leading to greater collaboration between university and hospital libraries.

\section{Association services}

To ensure the viability of a professional association, it is important that membership in the association be perceived as providing value. When asked to rate the importance of the services and benefits of membership in CHLA / ABSC, the three most important benefits were CE, the annual conference, and networking opportunities. Figure 1 depicts respondents' answers to this question, as rated on a five point scale (no opinion, not important, somewhat important, important, and very important).

$\mathrm{CE}$ was rated the highest, with half of the respondents indicating it was either "very important" $(72,50.7 \%)$ or "important" (53, 37.3\%). The annual conference also scored very high, with $49.7 \%$ of the respondents rating it as "very important" and 35\% rating it as "important". Networking opportunities were considered "very important" to $37.1 \%$ of respondents and "important" to $50.3 \%$ of respondents. Ranked at the lower end of the scale, in descending order, were online discussion, the membership directory, grants and scholarships, and the awards for excellence. The lesser support for these benefits and services warrants further investigation. Other comments included the importance of collaboration and exchange of information with MLA and other health library associations, as well as affordable online CE.

\section{Communication}

CHLA / ABSC currently communicates with its members in a variety of ways. In asking which communication methods are most useful, the overwhelming preference was for online $\mathrm{CE}$, which $70 \%$ of respondents indicated was "very useful". Respondents commented that "online CE is an affordable alternative for those who cannot get to conferences and (or) those who live in rural areas". Figure 2 demonstrates the usefulness of each of CHLA / ABSC methods of communication, as rated on a four point scale of not sure (1), not at all useful (2), somewhat useful (3), and very useful (4).

In addition to online $\mathrm{CE}$, other favoured means of communication were CHLA / ABSC's website (56.4\% "very useful"), e-News (52.5\% "very useful"), guidelines (47.1\% "very useful" and 39.3\% "somewhat useful"), and fact sheets $(40.4 \%$ "very useful" and $51.8 \%$ "somewhat useful"). The high valuation for fact sheets and guidelines is surprising given that many of the existing fact sheets and

Fig. 1. Importance of the services and benefits of membership in CHLA / ABSC.

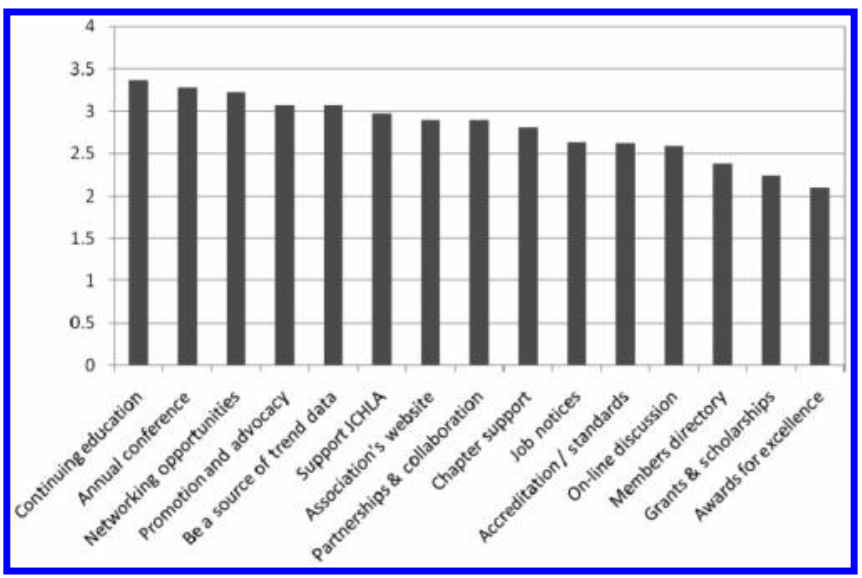


Fig. 2. Usefulness of methods for providing information and networking opportunities.

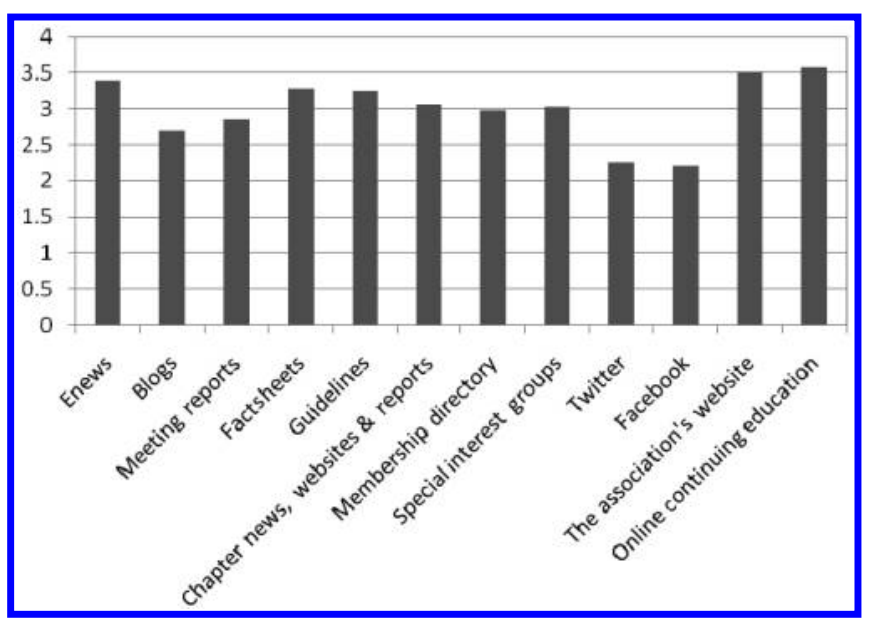

guidelines are dated. Social media (Twitter and Facebook) were found by $45.5 \%$ of respondents to be "not at all useful". CHLA / ABSC's social media communication tools have only been active for the last few years, and some members are firewalled from accessing social media websites from their workplace. CHLA / ABSC's Board will follow-up to further examine preferred methods of communication.

When asked about the value of being a CHLA / ABSC member compared with the cost of membership, $44.9 \%$ of respondents felt they receive "good value" and $24.6 \%$ felt they receive "very good value". Nearly $60 \%$ of respondents indicated they could "influence somewhat" or "influence greatly" the Association's policies and directions. Members also indicated that the Association is responsive to their concerns (60.1\% "responsive" and 33.8\% "somewhat responsive"), and only $6 \%$ believed the Association is "not responsive" to their concerns. Respondents also used the comments section of these questions to reiterate the common themes described in the Trends section, including the need and desire for more affordable, online $\mathrm{CE}$ and the need for advocacy tools, particularly in hospital libraries.

\section{Demographics}

The 2001 survey results suggested that CHLA / ABSC had an aging membership. In 2010, however, while onethird of the survey respondents were in the 50-59 age range $(35.7 \%)$, one-third were under 40 years of age $(34.3 \%)$. CHLA / ABSC membership therefore appears to have a healthy balance of older and younger members. Table 1 compares the age range of health information professionals from 2001 to the present. In 2001, concerns were identified about the aging of the profession, with the highest two age groups being $40-49$ years $(35.7 \%)$ and $50-59$ years $(30.5 \%)$. Although the 50-59 age range is still the largest age group in 2010 , the second highest age range represents a younger generation (30-39 years, 28.6\%).

When asked how many years of work experience respondents had as health librarians or health information professionals, $29.3 \%$ of respondents indicated they had
Table 1. Comparison of the age range of survey respondents in 2001 and 2010.

\begin{tabular}{lll}
\hline Age range & 2001 response $(\%)$ & 2010 response $(\%)$ \\
\hline $20-29$ & 9.5 & 5.7 \\
$30-39$ & 21.9 & $\mathbf{2 8 . 6}$ \\
$40-49$ & $\mathbf{3 5 . 7}$ & 18.6 \\
$50-59$ & $\mathbf{3 0 . 5}$ & $\mathbf{3 5 . 7}$ \\
$60-69$ & 2.3 & 7.9 \\
$70+$ & 0 & 0 \\
Not provided & 0 & 3.6 \\
\hline
\end{tabular}

1-5 years experience, $21.4 \%$ had $6-10$ years experience, $37.1 \%$ had more than 15 years experience, and only $9.3 \%$ had 11-15 years experience. Again this is indicative of a healthy balance of new and more experienced health information professionals. Also of interest is the increase in Master's degrees (71\% in 2001 compared with $87 \%$ in $2010)$ and the decrease in college diplomas (18\% in 2001 compared with $7.2 \%$ in 2010). This could indicate an increase in the number of librarians within the health sector, or it could demonstrate that the survey did not reach library technicians.

\section{Conclusion}

Advocacy, professional development, and networking are identified as three priorities in CHLA / ABSC's mission statement. These three themes were raised time and again in this survey of Canadian health information professionals. Listed in order of importance, survey respondents articulated the need for the following:

1. affordable, accessible (online) CE;

2. advocacy for health information professionals and advocacy within the greater Canadian library community;

3. support for the Canadian Virtual Health Library and equitable access to electronic health resources; and

4. accreditation and standards for health libraries and librarians.

Woven throughout these themes was a strong mandate for CHLA / ABSC to facilitate increased partnering, networking, and collaboration. Many respondents, especially hospital and (or) solo librarians, articulated the need for increased communication between health information professionals, as well as the need to identify those with similar roles, functions, and challenges. Health information professionals are seeking enriched discussion on CanMedLib or a monthly e-bulletin that highlights activities of chapters across Canada, identifies useful resources, and discusses searching issues. There were requests for podcasting conference contributions, social networking, sharing educational materials, and continued support and development of the Mentorship Interest Group.

The CHLA / ABSC Board used the results from this survey as a foundation for the strategic planning session held on 23 September 2010 and ensured these four themes were a priority. Despite concerns from the 2001 survey about an aging profession, the Board noted more equitable 
distribution of age groups in the health library community. The Board will continue to identify the most suitable methods of communications with, and between, its members and will continue to actively seek input and feedback on the Association and its policies and directions.

\section{Reference}

1. Ellis P, Scott L, Tripp T. Taking the measure of ourselves. Part II: CHLA/ABSC survey of Canadian Health Information Professionals. BMC. 2002 Winter;24(2):87-92. Available from: http://www.chla-absc.ca/survey/measure_1.pdf.
2. Crawford D, Crawford DS. CHLA/ABSC 25 years on. BMC. 2002;22(2):71-3.

3. Kharouba D, Powelson S, Slater L. The value of membership: the CHLA/ABSC 2008 membership survey. JCHLA/JABSC. 2008;29:47-50. Available from: http://pubservices.nrc-cnrc.ca/ rp-ps/absres.jsp?jcode $=$ jchla\&ftl $=\mathrm{c} 08-011 \&$ lang $=$ eng.

4. Canadian Health Libraries Association / Association des bibliothèques de la santé du Canada, Glover W (facilitator). Strategic plan 2008-2010: Results of a Strategic Planning Session by the Board of Directors. 2008 February. Available from: http://www.chla-absc.ca/node/241. 
This article has been cited by:

1. Dennett Liz, Chatterley Trish, Greyson Devon, Surette Soleil. 2013. Embedded Health Librarianship: The Canadian Landscape1. Journal of the Canadian Health Libraries Association 34:02, 61-68. [Abstract] [Full Text] [PDF] [PDF Plus] 